\title{
Pollen Germination in Different Genotypes of Gladiolus
}

\author{
Tul Bahadur Poon ${ }^{1}$, T.M Rao ${ }^{2}$, C. Aswath ${ }^{2}$,P.E.Rajasekharan ${ }^{2}$ and D.P.Kumar ${ }^{3}$ \\ ${ }^{1}$ Nepal Agricultural Research Council, Nepal \\ ${ }^{2}$ Indian Institute of Horticultural Research (IIHR), Bangalore, India \\ ${ }^{3}$ University of Agricultural Sciences, GKVK, Bangalore, India \\ e-mail:chetpun2002@yahoo.co.in
}

\begin{abstract}
Fresh pollen of 16 promising genotypes of gladiolus was tested for their pollen viability. Modified cellophane method was employed to assess the pollen viability. Pollen germination media consisted of $15 \%$ sucrose supplemented with 300 ppm calcium nitrate, 200 ppm magnesium sulphate, 100 ppm potassium nitrate and 100 ppm boric acid. Highly significant variations were observed for percentage of pollen germination, non-germinated pollen and sterile pollen. The highest pollen germination (76.41\%) was in genotype 'Hybrid selection 88-10-22, and did not differ significantly from Gladiolus callianthus (75.41\%), Sapna (75.10\%), Hybrid selection 86-32-11, (73.28 \%), Kum Kum (69.41\%), Poonam (69.22 \%), Hybrid selection 87-22-1 (67.87 \%), Hybrid selection 87-1-1 (67.61 \%), Psittacinus hybrid (64.64\%) and Darshan (63.97\%). The lowest non- germinated pollen (10.47\%) was in genotype Gladiolus callianthus, and insignificantly followed by Hybrid selection 88-10-22 with $18.77 \%$ and Hybrid selection 87-22-1 with $18.95 \%$. The lowest percentage of sterile pollen was noticed in genotype Sapna (2.82\%) followed by Poonam with $4.00 \%$ Hybrid selection 88-10-22 with 4.82\% and Hybrid selection 82-11-27 with 5.22\%.
\end{abstract}

Key words: Gladiolus, germination, pollen

\section{Introduction}

Assessment of pollen viability has direct relevance in hybridization as pollen of male parent takes part in the fertilization process. Therefore, pollen germination study is an important activity in order to determine the potentiality of male parent for fertilization and seed setting after crossing. Pollen viability is the ability of the pollen to perform its function of delivering male gametes to the embryo sac following compatible pollination (Shivanna et al. 1991). Proper pollination, pollen germination and favorable conditions leading to fertilization are the requisite conditions for seed production. Pollination makes a sense only when the process results in fertilization, which may be possible only when pollens germinate. In Gladiolus species, pollen viability is significantly reduced after $24 \mathrm{~h}$ of anthesis, approaching zero after 2 days (Koopowitz et al. 1984). The usefulness of modified cellophane method with some modifications obtained excellent pollen germination with uniform tube growth in
Gladiolus (Alexander \& Ganeshan 1989). Although a number of tests have been developed over the years to test pollen viability, standardization of a simple, rapid and dependable test such as modified cellophane method needs to be applied to assess the viability of different genotypes of Gladiolus.

\section{Methodology}

The florets of Gladiolus were tied with thread at floret bud loosening stage. On the next day, florets were harvested and brought to the laboratory. Pollen grains were extracted with blunt needle by scrapping the mature anthers and passing it transversely along the lope of the anther. Copious quantity of sticky pollens were collected on butter paper sheet. For drying purpose, pollens were placed under a table lamp of 60 watts for $30 \mathrm{~min}$. Seven layers of What man No.1 paper $\left(44 \mathrm{~mm}^{2}\right)$ were stapled in the form of a booklet. A 
cellophane sheet $\left(0.01 \mathrm{~mm}\right.$ thick) and $15 \mathrm{~mm}^{2}$ was inserted in the middle of top and second sheet of each booklet and soaked in prescribed pollen germination media for $15 \mathrm{~min}$. The media consisted of $15 \%$ sucrose supplemented with 300 parts per million (ppm) calcium nitrate $\left[\mathrm{Ca}\left(\mathrm{NO}_{3}\right)_{4} \cdot 2 \mathrm{H}_{2} \mathrm{O}\right], 200 \mathrm{ppm}$ magnesium sulphate $\left(\mathrm{Mg} \mathrm{So}_{4} 7 \mathrm{H}_{2} \mathrm{O}\right), 100$ ppm potassium nitrate $\left(\mathrm{KNO}_{3}\right)$ and 100 ppm boric acid. The booklets were removed by draining excess medium and were placed in $80 \mathrm{~mm}$ petridish. Top layer of booklet was carefully lifted and torn away. Then, exposed cellophane sheet surface was blotted dry with filter paper. Pollens were gently and uniformly dusted over the cellophane with a camel hairbrush. The booklet was enclosed in a petridish and surrounded by polythene sheet. The petridish was kept in a culture room for $3 \mathrm{~h}$ to maintain temperature of $25 \pm 2^{\circ} \mathrm{C}$ with $90 \%$ relative humidity. After incubation period, the cellophane sheets were removed from the booklet and placed on a glass microslide. One drop of versatile stain (Alexander, 1980) was dropped on cellophane sheet, and then a cover slip was placed gently over it and was observed under a microscope. Fresh pollens from promising 16 Gladiolus genotypes (8 cultivars, 6 hybrid selections and 2 species) were used in this experiment. The genotypes were Aarti, Arka Kesar, Darshan, Kum Kum, Poonam, Sapna, Shobha, Pink Friendship, Hybrid selection 82-11-27, Hybrid selection 84-7-11, Hybrid selection 86-32-11, Hybrid selection 87-1-1, Hybrid selection 87-22-1, Hybrid selection 88-10-22, Gladiolus callianthus and Psittacinus hybrid. The experiment was laid out in a completely randomized design replicated 4 times for fresh pollen germination. Germinated, nongerminated and sterile pollens were recorded. Original percentage values were transformed into angular or square root values and data were statistically analyzed.

Table 1. Pollen germination (\%) in different genotypes of Gladiolus

\begin{tabular}{l|l|c|c|c}
\hline S N & \multicolumn{1}{|c|}{ Genotypes } & $\begin{array}{l}\text { Pollen } \\
\text { Germination (\%) }\end{array}$ & $\begin{array}{c}\text { Percentage of non- } \\
\text { germinated pollen }\end{array}$ & $\begin{array}{c}\text { Percentage of } \\
\text { sterile pollen }\end{array}$ \\
\hline 1 & Aarti & $52.68(46.56)$ & $40.93(39.64)$ & $6.39(14.58)$ \\
2 & Arka Kesar & $53.09(46.75)$ & $39.42(38.86)$ & $7.48(15.82)$ \\
3 & Darshan & $63.97(53.15)$ & $29.71(32.95)$ & $6.31(14.49)$ \\
4 & Kum Kum & $69.41(56.44)$ & $23.25(28.76)$ & $7.34(15.64)$ \\
5 & Pink Friendship & $57.88(49.61)$ & $31.55(33.92)$ & $10.57(18.96)$ \\
6 & Poonam & $69.22(56.44)$ & $26.77(30.92)$ & $4.00(11.44)$ \\
7 & Sapna & $75.10(60.10)$ & $21.96(27.89)$ & $2.82(9.55)$ \\
8 & Shobha & $56.25(48.63)$ & $34.46(35.76)$ & $9.29(17.64)$ \\
9 & Hybrid selection 82-11-27 & $65.26(54.34)$ & $29.52(32.15)$ & $5.22(13.03)$ \\
10 & Hybrid selection 84-7-11 & $47.14(43.34)$ & $42.83(40.85)$ & $10.02(18.28)$ \\
11 & Hybrid selection 86-32-11 & $73.28(59.00)$ & $19.99(26.18)$ & $6.72(14.97)$ \\
12 & Hybrid selection 87-1-1 & $67.61(55.34)$ & $26.65(30.93)$ & $5.74(13.56)$ \\
13 & Hybrid selection 87-22-1 & $67.87(55.46)$ & $18.95(25.74)$ & $13.17(21.16)$ \\
14 & Hybrid selection 88-10-22 & $76.41(60.98)$ & $18.77(25.63)$ & $4.82(12.52)$ \\
15 & Gladiolus callianthus & $75.41(60.33)$ & $10.47(18.9)$ & $14.11(21.97)$ \\
16 & Psittacinus hybrid & $64.64(53.60)$ & $24.43(29.31)$ & $10.93(19.25)$ \\
& Mean & 64.73 & 27.48 & 7.81 \\
& F-test & $* *$ & $* *$ & 4.12 \\
& C.D. @1\% & 9.25 & 9.78 & \\
\hline
\end{tabular}

Figures within parenthesis are transformed values. ** Highly significant.

\section{Results}

Pollen germination: Among different genotypes of Gladiolus, highly significant $(\mathrm{p}<0.01)$ variations were recorded for this trait. Pollen germination varied from 47.14 to $76.41 \%$ with a mean value of $64.73 \%$ (Table 1). Highest germination (76.41\%) was in genotype Hybrid selection 88-10-22. It was statistically at par with Gladiolus callianthus (75.41\%), Sapna (75.10\%), Hybrid selection 86-32-
11 (73.28 \%), Kum Kum (69.41\%), Poonam (69.22 \%), Hybrid selection 87-22-1 (67.87\%), Hybrid selection 87-1-1 (67.61 \%), Psittacinus hybrid (64.64\%) and Darshan (63.97\%). On the contrary, the genotype Hybrid selection 84-7-11 recorded the lowest pollen germination (47.14\%). It was statistically at par with Aarti (52.68\%), Arka Kesar (53.09\%), Shobha (56.25\%) and Pink Friendship (57.88\%). 
Non-germinated pollen: Highly significant variations $(p<0.01)$ were found among different genotypes for non-germinated pollen production which varied from 10.47 to $42.83 \%$ with a mean value of $27.48 \%$. Genotype Gladiolus callianthus had the lowest nongerminated pollens $(10.47 \%)$ followed by Hybrid selection 88-10-22 (18.77\%) and Hybrid selection 8722-1 (18.95\%). Non-germinated pollens in 'Gladiolus callianthus' was statistically at par with Hybrid selection 88-10-22, Hybrid selection 87-22-1, Hybrid selection 86-32-11 and Sapna. Genotype Hybrid selection 84-7-11 showed the highest non-germinated pollen (42.83\%) followed by Aarti (40.93\%) and Arka Kesar (39.42\%).Genotype Hybrid selection 84-7-11 was statistically at par with Aarti, Arka Kesar, Shobha, Pink Friendship, Hybrid selection 82-11-27 and Darshan.

Sterile pollen: Different genotypes showed highly significant differences for sterile pollen (Table 1). Percentage varied from 2.82 to $14.11 \%$ with a mean value of $7.81 \%$. The lowest percentage of sterile pollen was noticed in genotype Sapna (2.82\%) followed by Poonam ( $4.00 \%$ ), Hybrid selection 88-10-22 (4.82\%) and Hybrid selection 82-11-27 (5.22\%). However, percentage of sterile pollen in Sapna was found statistically at par with Poonam, Hybrid selection 88-10-22, Hybrid selection 8211-27, and Hybrid selection 87-1-1. The highest percentage of sterile pollen (14.11\%) was in Gladiolus callianthus followed by Hybrid selection 87-22-1 (13.17\%), Psittacinus hybrid (10.93\%), Pink Friendship (10.57\%) and Hybrid selection 84-7-11 (10.02\%). However, percentage of sterile pollen in Gladiolus callianthus was found statistically at par with these four genotypes.

\section{Discussion}

In the present study although genotype Hybrid selection 88-10-22 had the highest percentage of pollen germination, it was not significantly different from some other genotypes, viz., Gladiolus callianthus, Sapna , Hybrid selection 86-32-11, Kum Kum, Poonam, Hybrid selection 87-22-1, Hybrid selection 87-1-1, Hybrid selection 82-11-27, Psittacinus hybrid and Darshan. Minimum percentage of pollen germination was found in genotypes, viz., Hybrid selection 84-7-11, Arka Kesar, Aarti and Shobha. Murthy (2001) also observed maximum percentage of pollen germination in genotypes, viz., Hybrid selection 87-22-1, Kum Kum, Darshan, Psittacinus hybrid and Hybrid selection 82-11-27 which is in agreement with the present study.
Non-germinated pollen percentage was rated as low in genotypes, viz., Gladiolus callianthus, Hybrid selection 88-10-22 and Hybrid selection 87-22-1. For this trait genotype Gladiolus callianthus differed significantly from the rest of the genotypes tested. Maximum non-germinated pollen was in genotypes viz., Hybrid selection 84-7-11, Aarti and Arka Kesar. With respect to percentage of non-germinated pollen genotype Hybrid selection 84-7-11 did not differ statistically from Aarti, Arka Kesar, Shobha and Pink Friendship.

In the present study variations in the percentage of pollen germination was from 47.14 to $76.41 \%$ among different genotypes of gladiolus tested. Pollen germination in 43 Iris cultivars and two wild types studied by Yabuya et al. (1982) ranged from 27.7 to $68.5 \%$. Seetharamu (1993) recorded the percentage of pollen germination of nine genotypes of tuberose ranging from 43.51 to $53.90 \%$. In general, variations in pollen germination exist in various genotypes of bulbous ornamental crops. Additionally, the pollen germination in a crop is not high and uniform as a number of factors, viz., genotype, constituents of pollen germination medium, floret and anther stage, moisture content of the pollen, incubation period and the purity during pollen germination would have an effect on pollen germination.

\section{References}

Alexander, M.P. 1980. A versatile stain for pollen, fungi, yeast and bacteria. Stain Technology 55:13-18.

Alexander, M.P. and S. Ganeshan. 1989. An improved cellophane method for in vitro germination of recalcitrant pollen. Stain Technology 64:225-227.

Koopowitz, H., R. Voss and C. O'neil. 1984. Long term storage of gladiolus pollen. HortScience $\mathbf{1 9}$ (4):513-514.

Murthy, S. 2001. Performance, dormancy and disease screening studies in Gladiolus. M.Sc. (Hort) thesis. University of Agricultural Sciences, Bangalore, India.

Seetharamu, G.K. 1993. Hybridization studies in tuberose. M.Sc. (Hort) thesis. University of Agricultural Sciences, Bangalore, India.

Shivanna, K.R., H.F. Linkskens and M. Creti. 1991. Pollen viability and pollen vigor. Theory and Appplied Genetics 81:38-42.

Yabuya, T., H. Takatsugi, T. Adachi and T. Nagatomo. 1982 Some characteristics of in vitro germination of Iris ensata Thumb. Pollen Bulletin 29(1):131-135. 
Nepal Journal of Science and Technology 11 (2010) 47-50 